\title{
Lower levels of Caveolin-1 and higher levels of endothelial nitric oxide synthase are observed in abdominal aortic aneurysm patients treated with simvastatin
}

\author{
Karolina Kowalska1,2, Dominika E. Habrowska-Górczyńska², Christoph Neumayer1, \\ Michael Bolliger ${ }^{1}$, Christoph Domenig ${ }^{1}$, Agnieszka W. Piastowska-Ciesielska2, \\ Ihor Huk' and Aleksandra Piechota-Polanczyk ${ }^{3 凶}$
}

1Department of Surgery, Division of Vascular Surgery, Medical University of Vienna, Vienna, Austria; ${ }^{2}$ Laboratory of Cell Cultures and Genomic Analysis, Department of Comparative Endocrinology, Medical University of Lodz, Łódź, Poland; ${ }^{3}$ Department of Medical Biotechnology, Faculty of Biochemistry, Biophysics and Biotechnology, Jagiellonian University, Kraków, Poland

\begin{abstract}
This study was undertaken to verify whether simvastatin modulates Cav-1/eNOS expression, and if this modulation is associated with changes in pro- and anti-inflammatory cytokine and Toll-like receptor 4 (TLR4) level in abdominal aortic aneurysm (AAA). It is a 1:2 case-control study of non-statin $(n=12)$ and simvastatin-treated patients $(n=24)$ who underwent open AAA repair. Simvastatin treatment decreased Cav-1 $(p<0.05)$ and increased eNOS expression $(p<0.01)$ in the AAA wall. These changes might be dose dependent. The changes in Cav-1 and eNOS were associated with a trend towards decreased IL- 6 and IL-17 concentration ( $p>0.05)$ and increased IL-10 concentration $(p=0.055)$; however, TLR4 expression was unaffected, suggesting that simvastatin influences Cav-1 and eNOS in the AAA wall by other mechanisms. Simvastatin may modulate Cav- 1 and eNOS expression in the aneurysmal wall, indicating a potentially beneficial role for statins in AAA patients.
\end{abstract}

Key words: Cav-1, eNOS, abdominal aortic aneurysm, simvastatin

Received: 23 August, 2017; revised: 17 February, 2018; accepted: 01 March, 2018; available on-line: 15 March, 2018

e-mail: aleksandra.piechota-polanczyk@uj.edu.pl

Abbreviations: AAA, abdominal aortic aneurysm; Ang II, angiotensin II; Akt, protein kinase B; Cav-1, caveolin-1; CRP, C-reactive protein; eNOS, endothelial nitric oxide synthase; $h E F-2$, translation elongation factor 2; IL-6, interleukin 6; IL-8, interleukin 8; IL-10, interleukin 10; IL-17, interleukin 17; LDL, low density lipoprotein; LPS, lipopolysaccharide; MMP-2, matrix metalloproteinase 2; MMP-9, matrix metalloproteinase 9; MAPK, mitogen activated protein kinase; NF-KB, nuclear factor kappa B; NO, nitric oxide; PVDF, polyvinylidene fluoride membranes; RNA, ribonucleic acid; RT-qPCR, Real-time quantitative polymerase chain reaction; TBST buffer, Trisbuffered saline-Tween 20 buffer; TLR2, Toll-like receptor 2; TLR4, Toll-like receptor 4; TNFa, tumor necrosis factor a

\section{INTRODUCTION}

Abdominal aortic aneurysm (AAA) is defined as a dilatation of the aorta to a diameter greater than $50 \%$ of normal (Johnston et al., 1991); it typically occurs in the infrarenal aorta (Takayama \& Yamanouchi, 2013) and in most cases is associated with atherosclerosis. A recent review of pharmaceutical treatments of AAA (Kokje et al., 2015) found that statins may have a beneficial effect. Statins are widely known to modulate the lipid profile, but the recent discovery of their pleiotropic effects has triggered new lines of research which indicate they may also have beneficial applications in the treatment of
AAAs (Mastoraki et al., 2012). Simvastatin, a commonlyused statin, was shown to possess a substantial potential for modulating interleukins IL-4, IL-6, IL-10, and tumor necrosis factor TNF- $\alpha$ (Piechota-Polanczyk et al., 2012), as well as the matrix metalloproteinase MMP-9 (Evans et al., 2007) and nuclear factor kappa B (NF-xB) in AAAs (Piechota-Polanczyk et al., 2012).

Endothelial nitric oxide synthase (eNOS) is the main producer of nitric oxide (NO) in the endothelium. Turbulent flow conditions result in its uncoupling, triggering the endothelial cell dysfunctions observed in many cardiovascular diseases (Huk et al., 1997; Kanai et al., 1995). Although elevated eNOS expression has a beneficial effect in the pathogenesis of AAA, its role seems to be more complex (Piechota-Polanczyk et al., 2015b). Under particular conditions, eNOS uncoupling might negatively correlate with the vasodilatory effect of NO and participate in AAA formation (Gao et al., 2012). In addition, the eNOS deficiency seen in atherosclerosis has been found to cause spontaneous aortic aneurysms in ApoE knock-out mice (Kuhlencordt et al., 2001).

Caveolin-1 (Cav-1) is a structural protein of the caveolae known to possess a functional role in cell signalling (Kowalska et al., 2016). In endothelial cells, Cav-1 participates in the regulation of eNOS signalling via modulation of eNOS activation. Cav-1 expression is positively correlated with atherosclerosis and obesity (Singh et al., 2011); it has been reported to modulate MMP-2 activity in heart tissue (Chow et al., 2007) and influence AAA formation through its functional relationship with angiotensin II (Ang II) receptors (Kowalska et al., 2016; Takayanagi et al., 2014). It might also act as an immunomodulatory agent via its action on $\mathrm{NF}-x \mathrm{~B}$ and TLR4 (Mirza et al., 2010), and may influence the effect of simvastatin (Almansob et al., 2012): simvastatin has been found to potentially downregulate Cav-1 expression and increase eNOS expression in the abdominal aorta of animals (Arora et al., 2012). Nevertheless, it is not known whether statins might cause a similar effect in AAA patients.

The aim of the study presented here was to determine whether simvastatin treatment changes the Cav-1/eNOS ratio in tissues of AAA patients. To verify the mechanism behind those changes, measurements were taken of the tissue levels of pro-inflammatory IL- 6 and IL-17 and of anti-inflammatory IL-10, as well as the TLR4 receptor, which are known to regulate Cav-1 expression (Jones et al., 2001; Weiss et al., 2015). 


\section{MATERIALS AND METHODS}

Patients. This study comprised 120 patients who underwent open AAA repair between September 2009 and December 2012 at the Department of Surgery, Medical University of Vienna, as previously described (PiechotaPolanczyk et al., 2015a).

From that cohort, a group was formed of patients treated with simvastatin or who had taken no statins for at least six months before the AAA repair procedure. The patients were then matched according to the AAA diameter. Finally, 12 "non-statin" patients and 24 simvastatin-treated patients were chosen to study the effects of simvastatin on Cav-1 and eNOS in AAA.

The following patients were excluded: those who had taken statins other than simvastatin; those who had taken non-steroidal anti-inflammatory drugs, except aspirin, in the medication list; those with chronic diseases such as liver diseases, inflammatory diseases or malignant diseases; those who were recreational drug users; those who were abusing alcohol.

Patient data was prospectively collected after obtaining written informed consent, and aneurysm wall tissue was harvested during surgery for retrospective analysis. $\mathrm{Pa}-$ tients were matched in a two (simvastatin) to one (nonstatin) ratio by age, sex, and AAA diameter (in the listed order). Twelve non-statin patients (10 men, two women) were included in the control group, and 24 patients who had received simvastatin (22 men, two women) in their medical history (20-40 mg daily for a minimum of six months) were included to the simvastatin group. AAA diameter was measured with pre-operative computed tomography angiography.

The study was approved by the local institutional ethics committee (EC 294/2009) at the Medical University of Vienna.

Tissue harvesting. The AAA samples were collected as described previously (Piechota-Polanczyk et al., 2013). After collection, the samples were immediately frozen in liquid nitrogen and stored at $-80^{\circ} \mathrm{C}$.

Enzyme-linked Immunosorbent Assays (ELISA) for eNOS, IL-6, IL-10, IL-17. First, $30 \mathrm{mg}$ samples of frozen aortic wall were grinded and subjected to protein extraction with the Mammalian Cell Lysis Kit according to the manufacturer's instructions (Sigma-Aldrich, USA). Following this, ELISA kits were used to assay the eNOS, IL-10, IL-17 (R\&D Systems, USA) and IL-6 (eBioscience, USA) content, according to the manufacturer's instructions. The samples were diluted where necessary. Absorbance was read at $450 \mathrm{~nm}$ (VICTOR3 1420, Perkin Elmer, USA). All assays were performed in duplicate.

Real-time quantitative polymerase chain reaction (RT-qPCR) for Cav-1, eNOS, TLR4. As with the protein analysis, $30 \mathrm{mg}$ of frozen aortic wall was used for RNA extraction with RNeasy Mini Kit (Qiagen, Germany) according to the manufacturer's instructions. cDNA was synthesized using a High-Capacity cDNA Reverse Transcription Kit (Thermo Fisher Scientific, USA). RTqPCR was conducted on an Applied Biosystems ${ }^{\circledR} 7500$ Real-Time PCR Systems (Thermo Fisher Scientific) using a Power SYBR ${ }^{\circledR}$ Green PCR Master Mix according to the manufacturer's instructions (Thermo Fisher Scientific). Primers were designed using Primer3 version 0.4.0 software (http://frodo.wi.mit.edu/). hEF-2: Sense primer: 5'GAGATCCAGTGTCCAGAGCAG3', Antisense primer: 5'CTCGTTGACGGGCAGATAGG3'; Cav-1: Sense primer: 5'AGTGCATCAGCCGTGTCTATTCCA3', Antisense primer: 5'TCTGCAAGT'TGATGCGGACATTGC3'; TLR4: Sense primer: 5'CA-
GAGTT'TCCTGCAATGGATCA3', Antisense primer: 5'GCT'TATCTGAAGGTGTTGCACAT3'; eNOS: Sense primer: 5'CCCGCTTCCTGTTTCT'TAGT3', Antisense primer: 5'GGCACAGTCCCT'TATGGTAAA3'. Eukaryotic translation elongation factor $2(h E F-2)$ was used as a reference gene for analysis. qPCR data was analyzed according to the Roche algorithm (Pfaffl et al., 2002). In order to avoid the detection of non-specific products for each reaction, melting curve analysis was performed. The relative expression of Cav-1, TLR4 and eNOS was expressed as a ratio of the gene of interest to a reference gene for each sample. All experiments were run in triplicate.

Western blot for Cav-1, eNOS, TLR4. A $30 \mu \mathrm{g}$ sample of protein was separated electrophoretically and transferred onto polyvinylidene fluoride membranes (PVDF) by wet transfer (Bio-Rad Laboratories, USA). Membranes were then blocked in 5\% fat-free milk for one hour prior to an overnight incubation at $4^{\circ} \mathrm{C}$ with a primary rabbit anti-Cav-1 polyclonal antibody, rabbit anti-NOS3 polyclonal antibody and goat anti-TLR4 polyclonal antibody (dilution 1:200; Santa Cruz, respectively) diluted in 1\% fat-free milk. Mouse anti- GAPDH monoclonal antibody was used as a reference (dilution 1:1000; Santa Cruz).

Next, the membranes were washed three times for 15 minutes with Tris-buffered saline-Tween 20 (TBST) buffer, and incubated for one hour with secondary antibodies conjugated with alkaline phosphatase: anti-rabbit $\operatorname{IgG}$, anti-mouse $\mathrm{IgG}$, anti-goat $\operatorname{IgG}$ (dilutions 1:15000; Sigma-Aldrich). The membranes were washed three times in TBST buffer, and the bands visualized using Novex ${ }^{\circledR}$ AP Chromogenic Substrate (Thermo Fisher Scientific). A densitometric analysis of protein expression levels was then conducted using ImageJ version 1.34 software (http://rsbinfo.nih.gov/ $\mathrm{ij} /$; USA). The results were calculated as the ratio of Cav-1, TLR4 and eNOS expression to the GAPDH expression. All experiments were conducted in triplicate for all patients.

Statistical analysis. Continuous demographic and biochemical data is presented as median, minimum and maximum, or mean \pm S.E.M. demographic categorical data was described with absolute frequencies and percentages. Comparisons between groups were performed using the Kruskal-Wallis test (or non-parametric MannWhitney U-test) and $\chi 2$ test depending on the normality of distribution. Two-way analysis of variance and the Dunns post hoc test were used to calculate differences. To calculate correlations, Spearman's rank correlation coefficient (r) test was used. Grubbs' test was performed to identify statistically significant outliers $(\phi<0.05)$, and these were excluded from the statistical analysis of the results (GraphPad Prism software).

\section{RESULTS}

\section{Patients' characteristics}

The non-statin and simvastatin patient data is presented in Table 1. The median aneurysm diameter was $56 \mathrm{~mm}(49-65 \mathrm{~mm})$ in the non-statin group and $55.5 \mathrm{~mm}(48-120 \mathrm{~mm})$ in the simvastatin group. The patients receiving statins had significantly lower total cholesterol $(p=0.026)$ and LDL cholesterol levels $(p=0.012)$. No differences in C-reactive protein (CRP), fibrinogen, creatinine, haemoglobin, or leukocyte levels were noticed (all $p \geq 0.05$ ). 
Table 1. Patient characteristics.

Patient characteristics are presented in the table. Data is presented as frequencies or median (minimum-maximum). Statistical significance for binary variables was assessed using generalized linear models, while metric values were analysed using linear mixed regression models. $P$-value $p<0.05$ was considered as statistically significant and is indicated in bold.

\begin{tabular}{|c|c|c|c|}
\hline & $\begin{array}{l}\text { Non-statin } \\
(n=12)\end{array}$ & $\begin{array}{l}\text { Simvastatin } \\
(n=24)\end{array}$ & $P$ value \\
\hline Age (range) & $69(50-75)$ & $68(55-80)$ & 1.000 \\
\hline AAA diameter [mm] (range) & $56(49-65)$ & $55.5(48-120)$ & 0.710 \\
\hline Body mass index $[\mathrm{kg} / \mathrm{m} 2]$ (range) & $27.5(23-37)$ & $26.0(22.0-34.5)$ & 0.282 \\
\hline Coronary artery disease & $4 / 12(33 \%)$ & $5 / 24(21 \%)$ & 0.815 \\
\hline Cerebrovascular artery disease & $8 / 12(67 \%)$ & $8 / 24(33 \%)$ & 0.239 \\
\hline Hypertension & $10 / 12(83 \%)$ & $21 / 24(87 \%)$ & 0.867 \\
\hline Nicotine & $8 / 12(67 \%)$ & $16 / 24(67 \%)$ & 0.780 \\
\hline CRP $[\mathrm{mg} / \mathrm{dl}]$ median (range) & $0.35(0.03-3.0)$ & $0.33(0.06-3.28)$ & 0.804 \\
\hline Cholesterol $[\mathrm{mg} / \mathrm{ml}]$ median (range) & $\begin{array}{l}236.5 \\
(143.0-267.0)\end{array}$ & $\begin{array}{l}192.5 \\
(110.0-264.0)\end{array}$ & 0.026 \\
\hline $\mathrm{HDL}[\mathrm{mg} / \mathrm{ml}]$ median (range) & $46.0(32.0-59.0)$ & $47.0(29.0-75.0)$ & 0.679 \\
\hline LDL [mg/dl] median (range) & $\begin{array}{l}141.7 \\
(79.2-181.0)\end{array}$ & $\begin{array}{l}110.0 \\
(56.0-169.0)\end{array}$ & 0.012 \\
\hline Creatinin $[\mathrm{mg} / \mathrm{dl}]$ median (range) & $1.15(0.76-1.48)$ & $1.1(0.78-4.0)$ & 0.703 \\
\hline Haemoglobin $[\mathrm{g} / \mathrm{dl}]$ median (range) & $14.0(13.0-15.7)$ & $13.6(12.4-18.0)$ & 1.000 \\
\hline Leucocytes $[\mathrm{mln} / \mathrm{ml}$ median (range) & $8.0(6.0-11.0)$ & $7.2(5.3-13.0)$ & 0.251 \\
\hline Fibrinogen $[\mathrm{mg} / \mathrm{dl}]$ median (range) & $\begin{array}{l}391.0 \\
(260.0-549.0)\end{array}$ & $\begin{array}{l}347.0 \\
(213.0-581.0)\end{array}$ & 0.136 \\
\hline
\end{tabular}

\section{Simvastatin decreases Cav-1 expression and dose- dependently increases eNOS in AAA wall}

eNOS and CAV-1 expression was evaluated on the protein and mRNA level. As Cav-1 is present at high levels in most of the cells, Western blot was sufficient to evaluate its level.

Our results indicated that simvastatin treatment modulates Cav-1 expression at the gene and protein level in the AAA wall (Fig. 1). After simvastatin treatment, expression of the Cav-1 gene and protein was approximately half that $(45 \%)$ of the non-treated group $(p=0.033$, Fig. 1). Additionally, a daily dose of $20 \mathrm{mg}$ simvastatin significantly decreased Cav-1 protein expression $(p<0.05)$ when compared to controls; however, no dose-dependent effect was visible.

In the caveolae, Cav-1 blocks the action of eNOS by binding to it. A decrease in Cav-1 was accompanied by a significant increase in eNOS: $p<0.01$ and $p<0.001$ for 20 $\mathrm{mg}$ and $40 \mathrm{mg}$ of simvastatin, respectively (Fig. 2B). No significant change in eNOS expression was observed at the gene level (Fig. 2A).

A statistically significant correlation was observed between the expression of Cav-1 and eNOS in simvastatintreated patients $(p=0.042$, Table 2 ) No other correlation between Cav-1, eNOS and cytokines was observed.

\section{Simvastatin's influence on Cav-1 and eNOS is not associated with changed cytokine levels in AAA wall}

To confirm whether a decrease in Cav-1 and an increase in eNOS is associated with changes in the proor anti-inflammatory cytokine profiles, the levels of IL6, IL-17 and IL-10 were analyzed (Fig. 3). Lower levels of IL- 6 tended to be observed in patients with higher doses of simvastatin (40 mg), although this relationship was not significant $(448.3 \pm 72.37 \mathrm{pg} / \mathrm{ml}$ in control vs.
$293.8 \pm 120.7 \mathrm{pg} / \mathrm{ml}$ in simvastatin, $p=0.055$ ) (Fig. 3A). Likewise, there was a tendency towards a lower IL-17 content following simvastatin treatment (37\% reduction): $60.21 \pm 16.12 \mathrm{pg} / \mathrm{ml}$ in controls vs. $38.31 \pm 7.624 \mathrm{pg} / \mathrm{ml}$ in the simvastatin group (Fig. 3B). In addition, the simvastatin group demonstrated a strong, dose-dependent tendency towards increasing IL-10 levels (Fig. 3C): Simvastatin at a dose of $40 \mathrm{mg}$ reduced the IL-10 level by $40 \%$ when compared to controls $(p=0.055)$.

\section{Simvastatin treatment does not influence TLR4 expression in the AAA wall}

Changes in Cav-1 are known to be associated with TLR4 stimulation (Wang et al., 2009). Therefore, in this

Table 2. Correlations of Cav-1, eNOS and cytokines in the simvastatin study group.

The correlation of the expression of Cav- 1 assessed by Western blot, eNOS expression assessed by ELISA, Cav-1 and eNOS gene expression assessed by RT-qPCR and cytokine level assessed by ELISA, were made with Spearman's correlation test calculated for the study group (simvastatin). $P<0.05$ was considered as statistically significant and is marked in bold, vs., versus, $\mathrm{R}_{\mathrm{s}}$-Spearman rank correlation coefficient.

\begin{tabular}{lll}
\hline & $\mathrm{R}_{\mathrm{s}}$ & $P$ value \\
\hline Cav-1 vs. eNOS & -0.1544 & 0.4583 \\
\hline IL-6 vs. eNOS & -0.09 & 0.6688 \\
\hline IL-10 vs. eNOS & 0.09652 & 0.6537 \\
\hline IL-17 vs. eNOS & -0.04162 & 0.8434 \\
\hline Cav-1 vs. eNOS & 0.2243 & 0.3035 \\
\hline IL-6 vs. Cav-1 & -0.1157 & 0.5905 \\
\hline IL-10 vs. Cav-1 & 0.1937 & 0.3759 \\
\hline IL-17 vs. Cav-1 & 0.1726 & 0.4199 \\
\hline
\end{tabular}




\section{A}
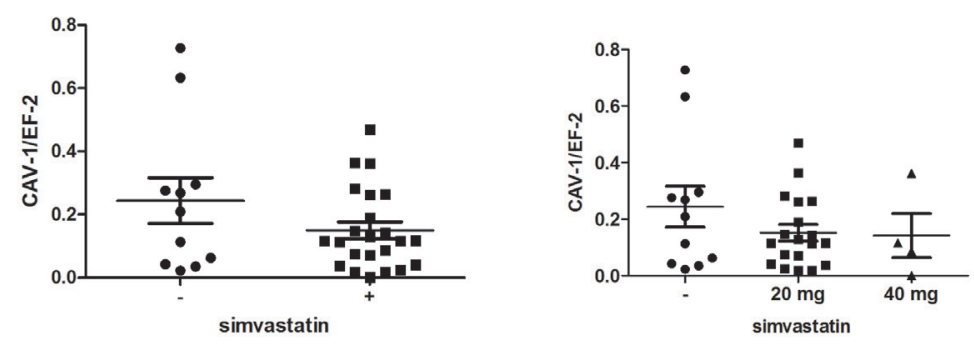

B
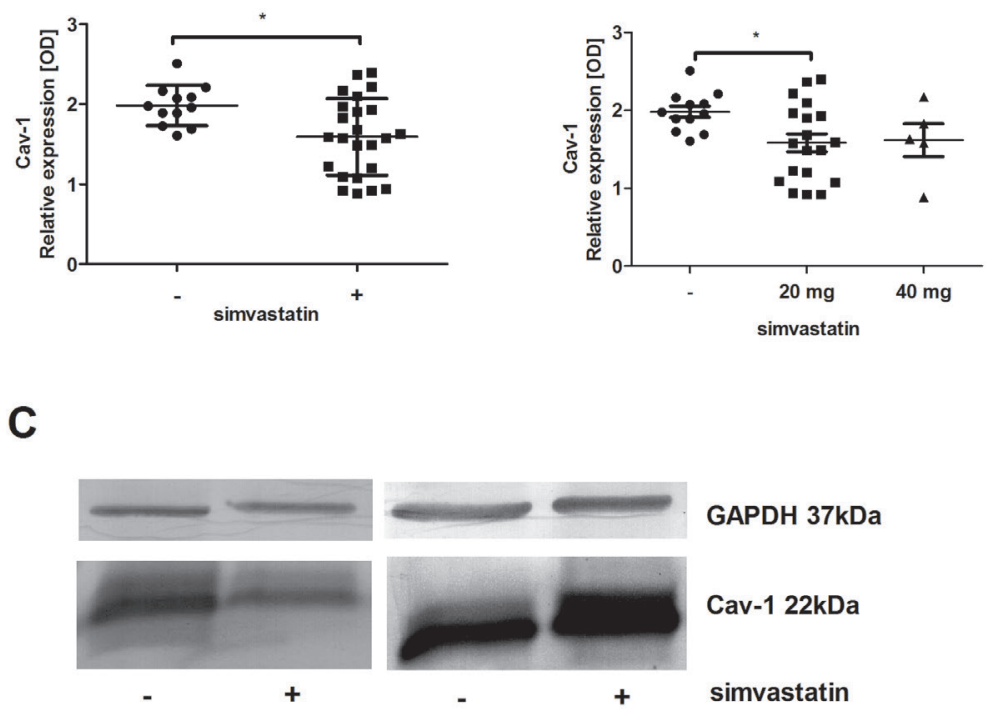

Figure 1. Simvastatin influence on the Cav-1 gene (A) and protein (B) expression.

The results from representative Western blots are presented in panel (C). Gene expression was evaluated with RT-qPCR, whereas protein expression was evaluated by the Western blot technique. Results are presented as mean \pm S.E. ${ }^{*} p<0.05$; Cav-1, caveolin- 1 ; EF-2, elongation factor 2; O.D., optical density.

study we examined whether simvastatin treatment influences the observed changes in Cav-1 and eNOS by influencing the TLR4 expression. However, simvastatin was not found to have any significant effect on TLR4 (Fig. 4).

\section{DISCUSSION}

Our study demonstrates that simvastatin treatment decreases Cav-1 level but significantly increases eNOS expression in patients with AAA. At rest, eNOS is inactive and anchored to the caveolae by Cav-1. A recent study found an elevated $\mathrm{Cav}_{-1}$ gene and protein expression to be associated with impaired eNOS activity in cardiovascular diseases (Ricchiuti et al., 2011). In addition, Cav-1 and eNOS gene polymorphisms have been identified in patients with arterial diseases, suggesting that these genes play a role in the development of intima thickness (Testa et al., 2012). Cav-1 was also proposed to play a critical role in a mouse model of AAA formation, as Cav-1 knockout mice did not develop Ang II-induced AAA (Takayanagi et al., 2014); the authors suggest that Cav-1 may induce an increase in the level of the ADAM17 metalloprotease, which further activates TNF- $\alpha$ and epithelial growth factor receptor, leading to AAA development (Takayanagi et al., 2014).

In addition, a decrease in Cav-1 and an increase in eNOS has been reported in endothelial tissue rather than in smooth muscle cells in rabbits on a high-fat diet following simvastatin treatment (Arora et al., 2012); however, no change in eNOS phosphorylation was detected, suggesting a possible role might be played by other mechanisms related to the antioxidative role of statins or accumulation of cGMP, which is an indicator of eNOSdependant NO bioavailability (Meda et al., 2010; Piechota-Polanczyk et al., 2012).

Our findings indicate that simvastatin has a dose-dependent influence on eNOS but not on Cav-1. Patients treated with $40 \mathrm{mg}$ of simvastatin demonstrated a significantly higher eNOS protein expression than those 
A

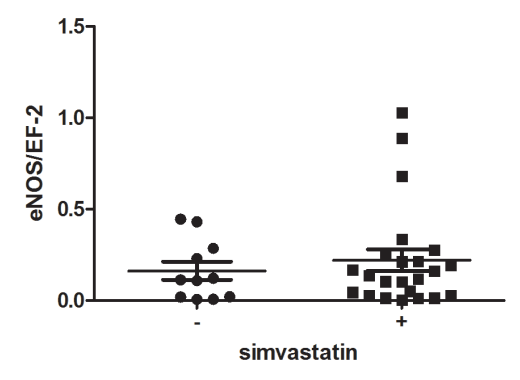

B

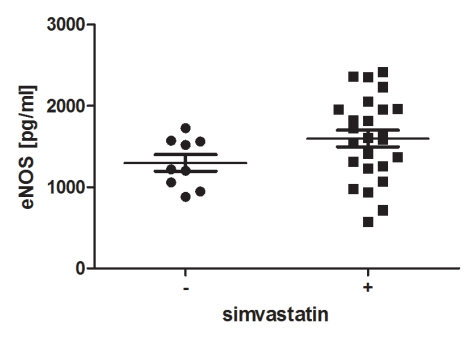

C
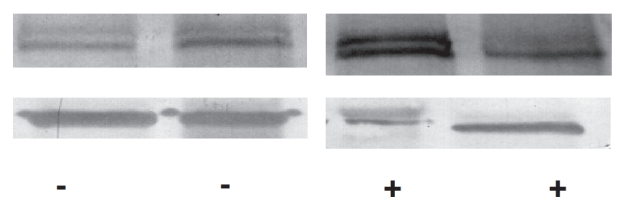

eNOS $140 \mathrm{kDa}$

GAPDH $37 \mathrm{kDa}$

simvastatin

Figure 2. Simvastatin influence on the eNOS gene (A) and protein (B) expression indicated a dose-dependent increase in eNOS.

The results from a representative Western blot are presented in panel (C). The result were obtained by RT-qPCR, ELISA and Western blot techniques and are presented as mean \pm S.E. ${ }^{* *} p<0.01 ;{ }^{* *} p<0.001$; eNOS, endothelial nitric oxide synthase; EF-2, elongation factor 2 ; O.D., optical density.

treated with $20 \mathrm{mg}$. Previous studies have also found statins to have a similar effect on endothelial cells, where simvastatin induced eNOS phosphorylation in a dosedependent manner, leading to further activation of Akt and AMPK (Hou et al., 2015). Those two intracellular proteins regulate eNOS activity (Ching et al., 2011; Sun et al., 2006).

However, the lack of dose dependence observed in our study for Cav-1 may be partially associated with the low number of patients treated with $40 \mathrm{mg}$ of simvastatin, as a partial trend was visible. Nonetheless, it should be stated that the effect of statins strongly depends on the cell type and the type of statin used. For example, simvastatin at a dose of $10 \mu \mathrm{M}$ increases eNOS and $[\mathrm{NO}] /\left[\mathrm{NOO}^{-}\right]$balance in human umbilical endothelial cells to the same extent as atorvastatin used at half of that dose $(5 \mu \mathrm{M})$ (Heeba et al., 2007). Furthermore, statins may have an anti- or pro-oxidative effect depending on their concentration and the type of cells on which they are acting (Loboda et al., 2006). The effect of simvastatin may also vary depending on the administered dose. For instance, studies on tumor vascularization found mice treated with a low dose of simvastatin $(0.2 \mathrm{mg} / \mathrm{kg})$ to have augmented eNOS phosphorylation when compared to mice treated with a higher dose (10 $\mathrm{mg} / \mathrm{kg}$ ); however, the higher dose was also associated with a significantly lower level of oxidative stress (Chen et al., 2013). Therefore, both the type and dose of statin may influence the results associated with the effect of simvastatin on Cav-1 and eNOS obtained in the study presented here.

Various factors regulate the changes in Cav-1 and eNOS, including cytokines. However, our results indicate that simvastatin treatment had no effect on the expression of pro-inflammatory IL-6, IL-17 or anti-inflammatory IL-10, three cytokines which play a key role in the development of AAA (Johnston et al., 2013; Jones et al., 2001). Despite this, previous studies have found that pro-inflammatory cytokines, especially IL-6, are associated with AAA formation and that lack of Cav-1 decreases 
A

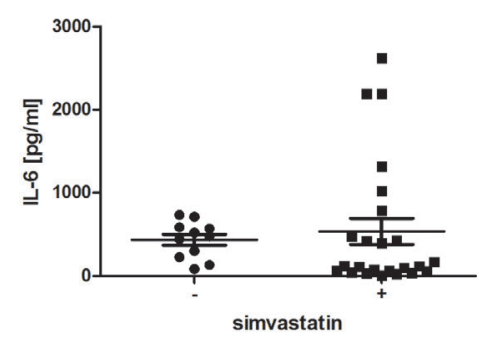

B

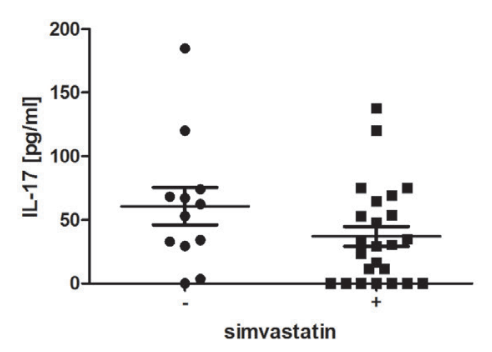

C

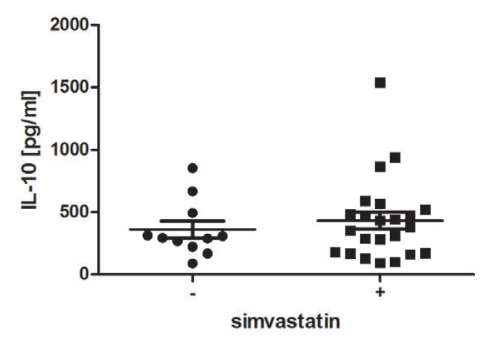

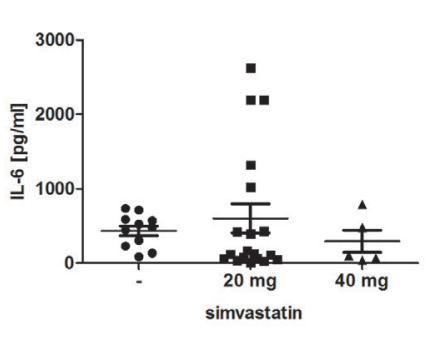
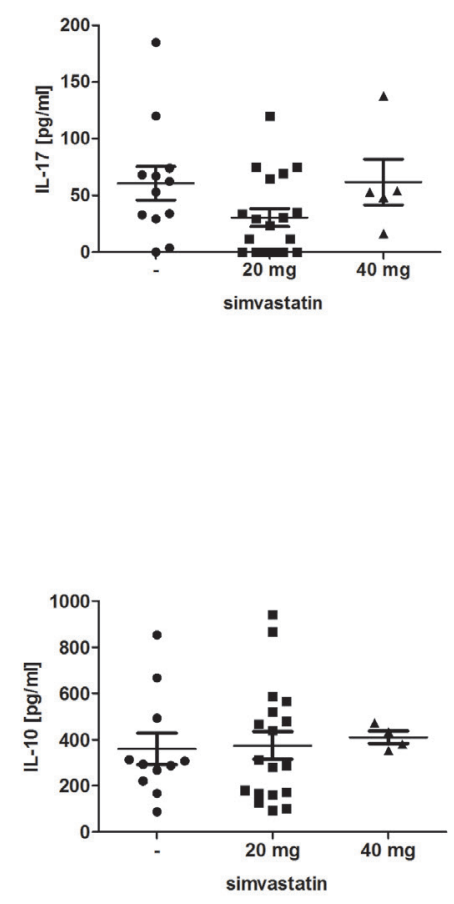

Figure 3. Simvastatin influence on IL-6 (A) IL-17 (B) and IL-10 (C) indicated no influence of simvastatin on those cytokines. Results are presented as mean \pm S.E. in $\mathrm{pg} / \mathrm{ml}$ after adjustment to protein concentration obtained by ELISA tests. IL, interleukin.

IL-6 level in the vascular media layer (Takayanagi et al., 2014). In addition, a negative correlation has been observed between Cav-1 and IL-17 in mice with ulcerative colitis (Weiss et al., 2015).

Additionally, the results of clinical trials indicate that patients subjected to non-coronary artery cardiac surgery demonstrated a reduced inflammatory response following perioperative, but not postoperative, treatment with simvastatin $(20 \mathrm{mg})$; this was reflected by lower IL-6, IL-8 and Cav-1 levels but higher eNOS expression and NO production. Increased eNOS levels were associated with higher Akt phosphorylation, while decreased Cav-1 was accompanied by reduced phosphorylation of p38 of MAPK in the heart tissue (Almansob et al., 2012). Therefore, the influence of simvastatin on Cav-1 and eNOS in acute inflammatory response in these states may be associated with changes in pro-inflammatory cytokine levels.

Finally, we wanted to verify if simvastatin treatment may change the TLR4 expression, which has been shown to regulate Cav-1 in cells (Wang et al., 2009). However, no difference in the TLR4 gene or protein expression was observed in the AAA tissue of the analysed groups. Hence, our results are in line with Azor et al. (Azor et al., 2011) who found that simvastatin or lovastatin administration had no influence on the TLR4 level in chronic idiopathic urticaria. In contrast, Moutzouri and coworkers (2012) report that a high dose of simvastatin $(40 \mathrm{mg})$ or the combination of a low dose of simvastatin/ezetimibe $(10 / 10 \mathrm{mg})$ reduces TLR2 and TLR4 membrane expression in patients with hypercholesterolemia treated with lipopolysaccharide (LPS). Also, at a dose of $80 \mathrm{mg} /$ day for four days, simvastatin reduced the influence of LPS-induced elevated TLR2 and TLR4 level on circulating monocytes and suppressed the activity of TNF- $\alpha$ and monocyte chemoattractant protein-1 (Niessner et al., 2006). The protective effect of statins on TLR4 receptors may be associated with the attenuation of the TLR4/NF-kB-mediated inflam- 
A
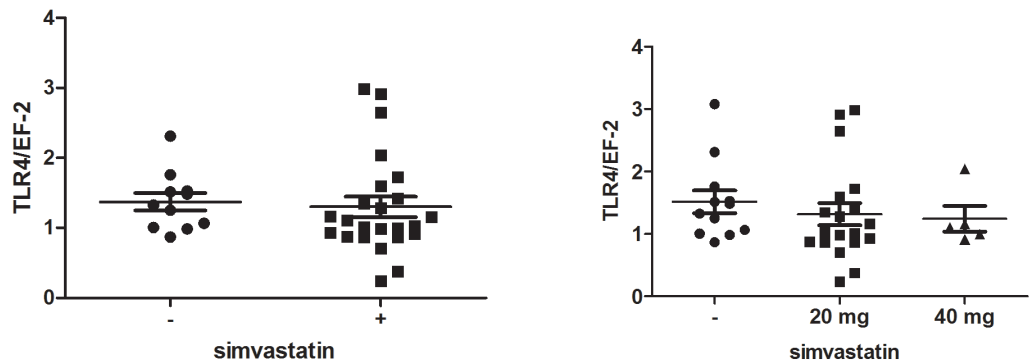

B
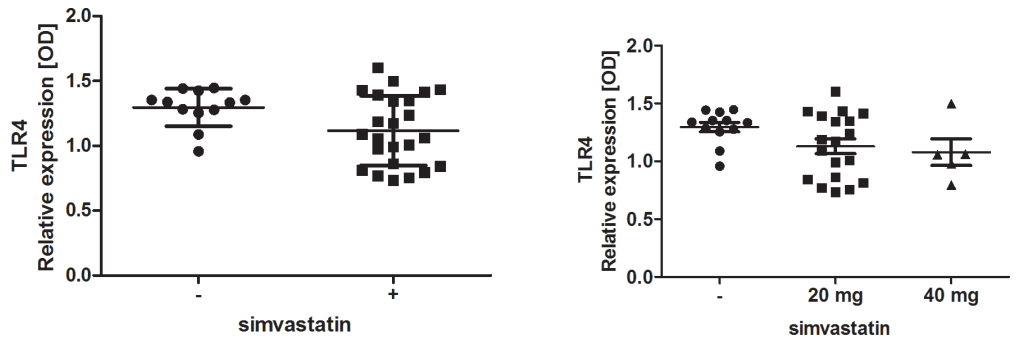

C

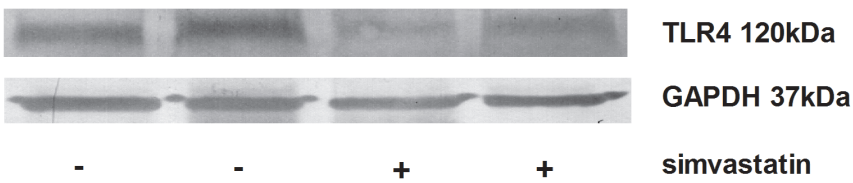

Figure 4. Simvastatin influence on the TLR4 gene (A) and protein (B) expression indicated no influence of the statin on the TLR4 expression.

The results from a representative Western blot are presented in panel (C). The results were obtained by RT-qPCR, ELISA and Western blot technique and are presented as mean \pm S.E. TLR4, toll-like receptor type 4; EF-2, elongation factor 2; O.D., optical density.

matory response, as shown for murine models of brain injury and lung inflammation (Chen et al., 2009; Shao et al., 2007).

To summarise, our findings indicate that patients displayed a significantly lower Cav-1 and higher eNOS expression in AAA tissue following simvastatin treatment. Therefore, simvastatin treatment may affect the Cav-1 and Cav-1/eNOS ratio in the AAA wall, suggesting that statins may play a potentially beneficial role in AAA patients. Nevertheless, further studies are necessary to verify the exact mechanisms behind those observations.

\section{Acknowledgements}

We are thankful to the Faculty of Foreign Languages at the Medical University of Lodz for the manuscript correction by a native speaker.

\section{Conflicts of Interest}

The authors declare no conflicts of interest.

\section{Acknowledgements of Financial Support}

This study was supported by grant number 181110 from the Medical University of Vienna, Department of Surgery and Medical University of Lodz grant number 503/0-078-04/503-01-004. The Faculty of Biochemistry, Biophysics and Biotechnology of the Jagiellonian University is a partner of the Leading National Research Center (KNOW), supported by the Ministry of Science and Higher Education.

\section{REFERENCES}

Almansob MA, Xu B, Zhou L, Hu XX, Chen W, Chang FJ, Ci HB, Yao JP, Xu YQ, Yao FJ, Liu DH, Zhang WB, Tang BY, Wang ZP, Ou JS (2012a) Simvastatin reduces myocardial injury undergoing noncoronary artery cardiac surgery: a randomized controlled trial. Arterioscler Thromb Vasc Biol 32: 2304-2313. doi: 10.1161/ATVBAHA.112.252098

Arora R, Hare DL, Zulli A (2012) Simvastatin reduces endothelial NOS: caveolin-1 ratio but not the phosphorylation status of eNOS in vivo. J Atheroscler Thromb 19: 705-711 
Azor MH, dos Santos JC, Futata EA, de Brito CA, Maruta CW, Rivitti EA, da Silva Duarte AJ, Sato MN (2011) Statin effects on regulatory and proinflammatory factors in chronic idiopathic urticaria. Clin Exp Immunol 166: 291-298. doi: 10.1111/j.1365-2249.2011.04473.x

Chen G, Zhang S, Shi J, Ai J, Qi M, Hang C (2009) Simvastatin reduces secondary brain injury caused by cortical contusion in rats: possible involvement of TLR4/NF-kappaB pathway. Exp Neurol 216: 398-406. doi: 10.1016/j.expneurol.2008.12.019

Chen Y, Zhang S, Peng G, Yu J, Liu T, Meng R, Li Z, Zhao Y, Wu G (2013) Endothelial NO synthase and reactive oxygen species mediated effect of simvastatin on vessel structure and function: pleiotropic and dose-dependent effect on tumor vascular stabilization. Int J Oncol 42: 1325-1336. doi: 10.3892/ijo.2013.1833

Ching LC, Kou YR, Shyue SK, Su KH, Wei J, Cheng LC, Yu YB, Pan CC, Lee TS (2011) Molecular mechanisms of activation of endothelial nitric oxide synthase mediated by transient receptor potential vanilloid type 1. Cardiovasc Res 91: 492-501. doi: 10.1093/cvr/cvr104

Chow AK, Cena J, El-Yazbi AF, Crawford BD, Holt A, Cho WJ, Daniel EE, Schulz R (2007) Caveolin-1 inhibits matrix metalloproteinase-2 activity in the heart. J Mol Cell Cardiol 42: 896-901. doi: 10.1016/j.yjmcc.2007.01.008

Evans J, Powell JT, Schwalbe E, Loftus IM, Thompson MM (2007) Simvastatin attenuates the activity of matrix metalloprotease- 9 in aneurysmal aortic tissue. Eur J V asc Endovasc Surg 34: 302-303. doi: 10.1016/j.ejvs.2007.04.011

Gao L, Siu KL, Chalupsky K, Nguyen A, Chen P, Weintraub NL, Galis Z, Cai H (2012) Role of uncoupled endothelial nitric oxide synthase in abdominal aortic aneurysm formation: treatment with folic acid. Hypertension 59: 158-166. doi: 10.1161/HYPERTENSIONAHA.111.181644

Heeba G, Hassan MK, Khalifa M, Malinski T (2007) Adverse balance of nitric oxide/peroxynitrite in the dysfunctional endothelium can be reversed by statins. J Cardiovasc Pharmacol 50: 391-398. doi: 10.1097/FJC.0b013e31811f3fd0

Hou HH, Liao YJ, Hsiao SH, Shyue SK, Lee TS (2015) Role of phosphatase activity of soluble epoxide hydrolase in regulating simvastatin-activated endothelial nitric oxide synthase. Sci Rep 5: 13524. doi: $10.1038 /$ srep 13524

Huk I, Nanobashvili J, Neumayer C, Punz A, Mueller M, Afkhampour K, Mittlboeck M, Losert U, Polterauer P, Roth E, Patton S, Malinski T (1997) L-arginine treatment alters the kinetics of nitric oxide and superoxide release and reduces ischemia/reperfusion injury in skeletal muscle. Circulation 96: 667-675

Johnston KW, Rutherford RB, Tilson MD, Shah DM, Hollier L, Stanley JC (1991) Suggested standards for reporting on arterial aneurysms. Subcommittee on Reporting Standards for Arterial Aneurysms, Ad Hoc Committee on Reporting Standards, Society for Vascular Surgery and North American Chapter, International Society for Cardiovascular Surgery. I V asc Surg 13: 452-458

Johnston WF, Salmon M, Su G, Lu G, Stone ML, Zhao Y, Owens GK, Upchurch GR, Jr., Ailawadi G (2013) Genetic and pharmacologic disruption of interleukin-1beta signaling inhibits experimental aortic aneurysm formation. Arterioscler Thromb V asc Biol 33: 294-304. doi: 10.1161/ATVBAHA.112.300432

Jones KG, Brull DJ, Brown LC, Sian M, Greenhalgh RM, Humphries SE, Powell JT (2001) Interleukin-6 (IL-6) and the prognosis of abdominal aortic aneurysms. Circulation 103: 2260-2265

Kanai AJ, Strauss HC, Truskey GA, Crews AL, Grunfeld S, Malinski T (1995) Shear stress induces ATP-independent transient nitric oxide release from vascular endothelial cells, measured directly with a porphyrinic microsensor. Circ Res 77: 284-293

Kokje VB, Hamming JF, Lindeman JH (2015) Editor's choice - pharmaceutical management of small abdominal aortic aneurysms: a systematic review of the clinical evidence. Eur J V asc Endovasc Surg 50: 702-713. doi: 10.1016/j.ejvs.2015.08.010

Kowalska K, Nowakowska M, Dominska K, Piastowska-Ciesielska AW (2016) Coexpression of CAV-1, AT1-R and FOXM1 in prostate and breast cancer and normal cell lines and their influence on metastatic properties. Acta Biochim Pol 63: 493-499. doi: 10.18388/ abp.2015_1016

Kuhlencordt PJ, Gyurko R, Han F, Scherrer-Crosbie M, Aretz TH, Hajjar R, Picard MH, Huang PL (2001) Accelerated atherosclerosis, aortic aneurysm formation, and ischemic heart disease in apolipoprotein E/endothelial nitric oxide synthase double-knockout mice. Circulation 104: 448-454

Loboda A, Jazwa A, Jozkowicz A, Dorosz J, Balla J, Molema G, Dulak J (2006) Atorvastatin prevents hypoxia-induced inhibition of endothelial nitric oxide synthase expression but does not affect heme oxygenase-1 in human microvascular endothelial cells. Atherosclerosis 187: 26-30. doi: 10.1016/j.atherosclerosis.2006.03.015

Mastoraki ST, Toumpoulis IK, Anagnostopoulos CE, Tiniakos D, Papalois A, Chamogeorgakis TP, Angouras DC, Rokkas CK (2012) Treatment with simvastatin inhibits the formation of abdomi- nal aortic aneurysms in rabbits. Ann Vasc Surg 26: 250-258. doi: 10.1016/j.avsg.2011.09.003

Meda C, Plank C, Mykhaylyk O, Schmidt K, Mayer B (2010) Effects of statins on nitric oxide/cGMP signaling in human umbilical vein endothelial cells. Pharmacol Rep 62: 100-112

Mirza MK, Yuan J, Gao XP, Garrean S, Brovkovych V, Malik AB, Tiruppathi C, Zhao YY (2010) Caveolin-1 deficiency dampens Tolllike receptor 4 signaling through eNOS activation. Am J Pathol 176: 2344-2351. doi: 10.2353/ajpath.2010.091088

Moutzouri E, Tellis CC, Rousouli K, Liberopoulos EN, Milionis HJ, Elisaf MS, Tselepis AD (2012) Effect of simvastatin or its combination with ezetimibe on Toll-like receptor expression and lipopolysaccharide-induced cytokine production in monocytes of hypercholesterolemic patients. Atherosclerosis 225: 381-387. doi: 10.1016/j. atherosclerosis.2012.08.037

Niessner A, Steiner S, Speidl WS, Pleiner J, Seidinger D, Maurer G, Goronzy JJ, Weyand CM, Kopp CW, Huber K, Wolzt M, Wojta J (2006) Simvastatin suppresses endotoxin-induced upregulation of toll-like receptors 4 and 2 in vivo. Atherosclerosis 189: 408-413. https://doi.org/10.1016/j.atherosclerosis.2005.12.022

Pfaffl MW, Horgan GW, Dempfle L (2002) Relative expression software tool (REST) for group-wise comparison and statistical analysis of relative expression results in real-time PCR. Nucleic Acids Res 30: e36.

Piechota-Polanczyk A, Goraca A, Demyanets S, Mittlboeck M, Domenig C, Neumayer C, Wojta J, Nanobachvili J, Huk I, Klinger M (2012) Simvastatin decreases free radicals formation in the human abdominal aortic aneurysm wall via NF-kappaB. Eur J V asc Endovasc Surg 44: 133-137. doi: 10.1016/j.ejvs.2012.04.020

Piechota-Polanczyk A, Demyanets S, Nykonenko O, Huk I, Mittlboeck M, Domenig CM, Neumayer C, Wojta J, Nanobachvili J, Klinger M (2013) Decreased tissue levels of cyclophilin A, a cyclosporine a target and phospho-ERK1/2 in simvastatin patients with abdominal aortic aneurysm. Eur J V asc Endovasc Surg 45: 682-688. doi: 10.1016/j.ejvs.2013.02.015

Piechota-Polanczyk A, Demyanets S, Mittlboeck M, Hofmann M, Domenig CM, Neumayer C, Wojta J, Klinger M, Nanobachvili J, Huk I (2015a) The influence of simvastatin on NGAL, matrix metalloproteinases and their tissue inhibitors in human intraluminal thrombus and abdominal aortic aneurysm tissue. Eur J V asc Endovasc Surg 49: 549-555. doi: 10.1016/j.ejvs.2015.02.011

Piechota-Polanczyk A, Jozkowicz A, Nowak W, Eilenberg W, Neumayer C, Malinski T, Huk I, Brostjan C (2015b) The Abdominal aortic aneurysm and intraluminal thrombus: current concepts of development and treatment. Front Cardiovasc Med 2: 19. doi: 10.3389/ fcrm.2015.00019

Ricchiuti V, Lapointe N, Pojoga L, Yao T, Tran L, Williams GH, Adler GK (2011) Dietary sodium intake regulates angiotensin II type 1 , mineralocorticoid receptor, and associated signaling proteins in heart. I Endocrinol 211: 47-54. doi: 10.1530/JOE-10-0458

Shao H, Shen Y, Liu H, Dong G, Qiang J, Jing H (2007) Simvastatin suppresses lung inflammatory response in a rat cardiopulmonary bypass model. Ann Thorac Surg 84: 2011-2018. doi: 10.1016/j.athoracsur.2007.07.022

Singh P, Peterson TE, Sert-Kuniyoshi FH, Jensen MD, Somers VK (2011) Leptin upregulates caveolin-1 expression: implications for development of atherosclerosis. Atherosclerosis 217: 499-502. doi: 10.1016/j.atherosclerosis.2010.10.012

Sun W, Lee TS, Zhu M, Gu C, Wang Y, Zhu Y, Shyy JY (2006) Statins activate AMP-activated protein kinase in vitro and in vivo. Circulation 114: 2655-2662. doi: 10.1161/CIRCULATIONAHA.106.630194

Takayama T, Yamanouchi D (2013) Aneurysmal disease: the abdominal aorta. Surg Clin North Am 93: 877-891. doi: 10.1016/j. suc.2013.05.005

Takayanagi T, Crawford KJ, Kobayashi T, Obama T, Tsuji T, Elliott KJ, Hashimoto T, Rizzo V, Eguchi S (2014) Caveolin 1 is critical for abdominal aortic aneurysm formation induced by angiotensin II and inhibition of lysyl oxidase. Clin Sci (Lond) 126: 785-794. doi: 10.1042/CS20130660

Testa A, Spoto B, Sanguedolce MC, Parlongo RM, Pisano A, Tripepi G, Benedetto FA, Mallamaci F, Zoccali C (2012) eNOS and caveolin-1 gene polymorphisms interaction and intima media thickness: a proof of concept study in ESRD patients. Am J Hypertens 25: 103 108. doi: 10.1038 /ajh.2011.178

Wang XM, Kim HP, Nakahira K, Ryter SW, Choi AM (2009) The heme oxygenase- $1 /$ carbon monoxide pathway suppresses TLR4 signaling by regulating the interaction of TLR4 with caveolin-1. J Immunol 182: 3809-3818. doi: 10.4049/jimmunol.0712437

Weiss CR, Guan Q, Ma Y, Qing G, Bernstein CN, Warrington RJ, Peng Z (2015) The potential protective role of caveolin-1 in intestinal inflammation in TNBS-induced murine colitis. PLoS One 10: e0119004. doi: 10.1371/journal.pone.0119004 